\title{
Working in a Pandemic Hospital during COVID-19 Outbreak: Current Conditions and Depression, Anxiety, and Stress Levels
}

\author{
(1) Özlem Polat ${ }^{1}$, (1) Filiz Coşkun² \\ 1 University of Health Sciences Turkey, Bakırköy Dr. Sadi Konuk Training and Research Hospital, Clinic of Family Medicine, Istanbul,Turkey \\ 2istanbul University-Cerrahpaşa Institute of Graduate Studies, Department of Nursing Management, Istanbul, Turkey
}

\section{Abstract}

Objective: Healthcare workers (HCW), who actively participate in combating the coronavirus disease-2019 (COVID-19) epidemic, may experience rage and anxiety due to the high performance expected from them. This study aimed to reveal how working in a pandemic hospital affects the psychological status of healthcare professionals.

Methods: 446 HCW, working frontline in a pandemic hospital, were included the study. Questions including basic demographic data and exposure risks to COVID-19 and depression anxiety stress scale (DASS-21) were used as data collection tools. The forms were delivered online, and the responses were similarly collected.

Results: DASS-21 scores of 384 (86.1\%) HCW, who had contact with patients diagnosed with COVID-19, were found to be higher than HCW who did not have contact with the patients. When we evaluated the scores of DASS-21, the scores were higher in women ( $p<0.01)$, HCW diagnosed with COVID-19 among their colleagues $(p<0.01)$, and HCW with relatives diagnosed with COVID-19. Anxiety scores of nurses $(p<0.05)$ and single HCW, were also high $(\mathrm{p}<0.05)$.

Conclusion: While the world continues to fight the COVID-19 outbreak, HCW are emotionally affected in this intense process. Providing psychosocial support and intervention to cover all healthcare professionals should be targeted by decision makers.

Keywords: Healthcare worker, COVID-19 outbreak, depression anxiety stress scale

\section{INTRODUCTION}

In December 2019, coronavirus disease-2019 (COVID-19) and its newly diagnosed severe acute respiratory syndrome-coronavirus 2 (SARS-CoV-2) agent, responsible of developing pneumonia, first broke out in Wuhan, China. The clinical spectrum of SARS-CoV-2 infection appears to be wide, encompassing asymptomatic infection, mild upper respiratory tract illness, severe viral pneumonia with respiratory failure, and even death, with many patients being hospitalized with pneumonia in Wuhan (1).

Healthcare workers (HCW) are continually faced by factors such as infectious diseases and exposure to chemical and physical agents. As of 14 February, 2021, 108,153,741 cases were reported related to COVID-19, and 2,579,896 cases were reported in our country on the same date (2). In the 2002 SARS outbreak, 1.725 HCW have been infected. As of 11 February, 2020, 1.716 Chinese HCW was infected with COVID-19. HCW were diagnosed among the first 15 cases (3). As of 10 December, 2020, of 1,100,000 HCW, more than 120,000 were infected with COVID-19, according to the statement of the Turkish Ministry of Health (4).

HCW actively participating in combating the COVID-19 epidemic may be concerned with their families or coworkers contracting the virus or themselves. They may also experience rage, anger, anxiety, and insomnia due to the high performance expected from them (5). Being isolated, working in high-risk areas, and being in direct contact with infected people are common causes 
of trauma $(6,7)$. Widespread media coverage of the clinical course and mortality rate of the outbreak intensifies the personal risk. Working in a high temperature with two layers of protection and masks during long working hours increases the stress. Moreover, behaviors such as not eating or drinking to prevent being infected and not being able to go to the toilet during the busy working hours make the process difficult for HCW. These conditions exhaust the staff both physically and psychologically and cause increased stress (8). Work-related tension and exposure to high stress could cause physical, behavioral, emotional, and psychological problems, which can lead to chronic diseases (9). Work stress is defined as a situation that causes inadequacy in the abilities of the individual and creates tension on both the physical and psychological levels, which can lead to physiological depression and anxiety, headache, muscle tension, insomnia, and lack of attention. Stress and altered hormonal activity can cause a vicious cycle of insomnia. This vicious cycle was experienced during the SARS outbreak, and an improvement in the sleep cycles of the employees was observed only two weeks after the end of the crisis $(8,9)$.

Ensuring the safety, fulfillment, and support of HCW is important during an outbreak to protect them from depression, anxiety, and stress, which were manifested during the COVID-19 outbreak. Regarding COVID-19, it is important to identify the operations and situations that pose a risk to the employees, determine the processes that need to be improved, find solutions, and immediately implement the regulations and measures for the identified risks to provide the best health service and protect the health of HCW, who work devotedly, and their families.

\section{METHODS}

University of Health Sciences Turkey, Bakırköy Dr. Sadi Konuk Training and Research Hospital is a tertiary training and research hospital in Istanbul, which is the most populous city in Turkey. Our hospital's healthcare professionals work devotedly to serve this population. This is a prospective study, which included 446 HCW working in the frontline between May and September in our hospital. All individuals consented to participate in the study. A power analysis was performed to obtain meaningful results for our study. Out of $1.083 \mathrm{HCW}$ working in the frontline, 383 were included in the study. A form consisting of questions on basic demographic data and direct and indirect exposure risks to COVID-19 and depression anxiety stress scale (DASS-21) were used as data collection tools (10). The data collection tools were prepared via Google forms. They were delivered to healthcare professionals online, and the answers were collected in the same way. All subjects gave consent prior to registration. Two options are given on the informed consent page (yes/no). Subjects who selected "yes" were included in the study. We asked questions on basic demographic data and direct and indirect exposure risks to COVID-19 in Supplement 1 and used the DASS in Supplement 2.

DASS-21 was created by Lovibond and Lovibond, which is the shorter version of DASS-42 (11). The psychometric properties of the Turkish version of DASS-21 in normal and clinical samples were introduced by Saricam (12). In the normal sample, the testretest correlation coefficients $(r)$ were 0.68 for the depression subscale, 0.66 for the anxiety subscale, and 0.61 for the stress subscale. This scale is a 4-point Likert-type scale and consists of seven questions that measure "depression, stress, and anxiety dimensions". If the individual has five points or more from the depression subdimension, four points or more from the anxiety, and eight points or more from the stress, this indicates that he/ she has a relevant problem.

The Ethics Committee of the University of Health Sciences Turkey, Bakırköy Dr. Sadi Konuk Training and Research Hospital, approved the questionnaire and methodology for this study (approval number: 2020/145). The authors assert that all procedures contributing to this work comply with the ethical standards of University of Health Sciences Turkey, Bakırköy Dr. Sadi Konuk Training and Research Hospital and the Helsinki Declaration of 1975, as revised in 2008. The participants' consent to participate in the study was requested personally from each individual.

\section{Statistical Analysis}

Number Cruncher Statistical System (NCSS) 2007 (Kaysville, Utah, USA) program was used for the statistical analysis. Besides comparing descriptive statistical methods (mean, standard deviation, median, frequency, rate, minimum, and maximum), Mann-Whitney $U$ test was used for two groups of variables, which were non-normally distributed, to compare quantitative data. Kruskal-Wallis test was used for comparing three or more groups, which were non-normally distributed, and DunnBonferroni test was used to determine the group that caused the difference. Spearman's correlation analysis was used to evaluate the relationships between quantitative variables. A $p$ value less than 0.05 was considered statistically significant.

\section{RESULTS}

Our study included 446 people: $70.9 \%(n=316)$ women and 29.1\% ( $n=130)$ men, working at University of Health Sciences Turkey, Bakırköy Dr. Sadi Konuk Training and Research Hospital. The mean age was $32.7 \pm 8.65$, with an age range between 20 
and 64 years. It was observed that $24.9 \%$ of the participants were physicians; 39.7\%, nurses; 35.4\%, other professions (Table 1).

Regarding the direct and indirect COVID-19 exposure risks, it was observed that $58.1 \%$ of the subjects worked over 40 hours during the COVID-19 outbreak. 86.1\% ( $n=384)$ of the participants were in contact with patients diagnosed with COVID-19. 79.2\% $(n=304)$ of the participants, who were in contact with patients diagnosed with COVID-19, stated that the patients wore a surgical mask during contact. $88.8 \%(n=396)$ of HCW participating in the study stated that, among their colleagues, $37.2 \%(n=166)$ were diagnosed with COVID-19 in acquaintance out of workplace (Table 2).

During the COVID-19 outbreak, $40.1 \%$ of the subjects' units were changed. Changes in the assigned units were in the ER, 12.8\%

\begin{tabular}{|c|c|c|c|}
\hline \multirow{2}{*}{\multicolumn{2}{|c|}{$\begin{array}{l}\text { Table1. Distribution of descriptive prop } \\
n=446\end{array}$}} & rties & \\
\hline & & $\mathrm{n}$ & $\%$ \\
\hline \multirow{2}{*}{ Age (years) } & Avg. \pm SD & \multicolumn{2}{|c|}{$32.76 \pm 8.65$} \\
\hline & Min-max (med.) & \multicolumn{2}{|c|}{$20-64(30)$} \\
\hline \multirow{2}{*}{ Sex } & Female & 316 & 70.9 \\
\hline & Male & 130 & 29.1 \\
\hline \multirow{2}{*}{ Marital status } & Single & 242 & 54.3 \\
\hline & Married & 204 & 45.7 \\
\hline \multirow{3}{*}{$\begin{array}{l}\text { Partner's } \\
\text { profession } \\
(n=204)\end{array}$} & $\begin{array}{l}\text { Healthcare } \\
\text { professional }\end{array}$ & 69 & 33.8 \\
\hline & $\begin{array}{l}\text { Not a healthcare } \\
\text { professional }\end{array}$ & 114 & 55.9 \\
\hline & Unemployed & 21 & 10.3 \\
\hline \multirow{2}{*}{$\begin{array}{l}\text { People } \\
\text { responsible } \\
\text { for taking care } \\
(n=404)\end{array}$} & No & 173 & 42.8 \\
\hline & Yes & 231 & 57.2 \\
\hline \multirow{3}{*}{$\begin{array}{l}\text { Place to stay after } \\
\text { work }\end{array}$} & Home & 357 & 80.0 \\
\hline & $\begin{array}{l}\text { Where I set up with } \\
\text { my own means }\end{array}$ & 50 & 11.3 \\
\hline & $\begin{array}{l}\text { Where the } \\
\text { institution arranges }\end{array}$ & 39 & 8.7 \\
\hline \multirow{3}{*}{ Profession } & Physician & 111 & 24.9 \\
\hline & Nurse & 177 & 39.7 \\
\hline & Other & 158 & 35.4 \\
\hline \multirow{6}{*}{ Education level } & Attending physician & 55 & 12.2 \\
\hline & Physician assistant & 56 & 12.3 \\
\hline & Graduate & 44 & 10.1 \\
\hline & Undergraduate & 160 & 35.9 \\
\hline & Associate degree & 90 & 20.3 \\
\hline & High school & 41 & 9.2 \\
\hline
\end{tabular}

$(n=23)$, intensive care unit, 29.1\% $(n=52)$, inpatient clinic, 42.5\% $(\mathrm{n}=76)$, operating room, $0.6 \%(\mathrm{n}=1)$, and outpatient clinic, $15.1 \%$ $(\mathrm{n}=27)$ (Table 2).

The distribution of the answers given by the healthcare professionals who participated in the study to the questions of DASS-21 are shown in Table 3.

On evaluating the DASS-21 scores according to the descriptive features (Table 4), the DASS-21 scores of the women HCW were significantly higher than men $(p=0.008 ; p=0.001 ; p=0.001$; $p<0.01)$. The anxiety score of single HCW was statistically significantly higher than the married ones $(p=0.013 ; p<0.05)$.

\begin{tabular}{|c|c|c|c|}
\hline \multicolumn{2}{|l|}{$n=446$} & \multirow{2}{*}{$\begin{array}{l}\mathbf{n} \\
220\end{array}$} & \multirow{2}{*}{$\begin{array}{l}\% \\
49.3\end{array}$} \\
\hline \multirow{4}{*}{$\begin{array}{l}\text { Working experience } \\
\text { Med. } \pm \text { SD; } 9.76 \pm 9.25\end{array}$} & $1-5$ years & & \\
\hline & 6-10 years & 64 & 14.3 \\
\hline & $11-20$ years & 93 & 20.9 \\
\hline & $\geq 21$ years & 69 & 15.5 \\
\hline \multirow{2}{*}{$\begin{array}{l}\text { Weekly working hours (hr) } \\
\text { Avg. } \pm \text { SD; } 45.92 \pm 6.70\end{array}$} & $\leq 40$ hours & 187 & 41.9 \\
\hline & $>40$ hours & 259 & 58.1 \\
\hline \multirow{5}{*}{$\begin{array}{l}\text { Assigned unit before } \\
\text { pandemic }\end{array}$} & Emergency room & 64 & 14.3 \\
\hline & Intensive care unit & 38 & 8.5 \\
\hline & Inpatient services & 92 & 20.6 \\
\hline & Operating room & 127 & 28.5 \\
\hline & Outpatient units & 125 & 28.0 \\
\hline \multirow{2}{*}{$\begin{array}{l}\text { Change of unit during } \\
\text { pandemic }\end{array}$} & Yes & 179 & 40.1 \\
\hline & No & 267 & 59.9 \\
\hline \multirow{5}{*}{ Assigned unit $(n=179)$} & Emergency room & 23 & 12.8 \\
\hline & Intensive care unit & 52 & 29.1 \\
\hline & Inpatient services & 76 & 42.5 \\
\hline & Operating room & 1 & 0.6 \\
\hline & Outpatient units & 27 & 15.1 \\
\hline \multirow{2}{*}{$\begin{array}{l}\text { Contact with COVID-19 } \\
\text { patient }\end{array}$} & Yes & 384 & 86.1 \\
\hline & No & 62 & 13.9 \\
\hline \multirow{2}{*}{$\begin{array}{l}\text { Contact with mask wearing } \\
\text { COVID-19 patient }(n=384)\end{array}$} & Yes & 304 & 79.2 \\
\hline & No & 80 & 20.8 \\
\hline \multirow{2}{*}{$\begin{array}{l}\text { Colleagues diagnosed with } \\
\text { COVID-19 }\end{array}$} & Yes & 396 & 88.8 \\
\hline & No & 50 & 11.2 \\
\hline \multirow{2}{*}{$\begin{array}{l}\text { Acquaintances diagnosed } \\
\text { with COVID-19 outside work } \\
\text { place }\end{array}$} & Yes & 166 & 37.2 \\
\hline & No & 280 & 62.8 \\
\hline \multirow{2}{*}{ Chronic disease } & Yes & 80 & 17.9 \\
\hline & No & 366 & 82.1 \\
\hline \multirow{2}{*}{$\begin{array}{l}\text { Psychological support } \\
\text { request }\end{array}$} & Yes & 30 & 6.7 \\
\hline & No & 416 & 93.3 \\
\hline
\end{tabular}


There was a statistically significant difference among the anxiety and stress scores of the hospital staff according to their professional status $(p=0.023 ; p<0.05 ; p=0.004 ; p<0.01)$ According to the results of the dual comparison performed to determine the difference, the anxiety score of participating nurses was significantly higher than those in other professions $(p=0.023 ; p<0.05)$. The stress score of participating physicians or nurses was significantly higher than those in other professions $(p=0.030 ; p=0.007 ; p<0.05)$ (Table 4).

On evaluating COVID-19 exposure risk and DASS-21 scores (Table 5), DASS-21 scores of the coworkers diagnosed with COVID-19 were statistically significantly higher than colleagues not diagnosed with COVID-19 $(p=0.001 ; p<0.01)$.

DASS-21 scores of HCW with any relatives diagnosed with COVID-19 outside of the workplace were statistically significantly higher than those with relatives not diagnosed with COVID-19 $(p=0.008 ; p<0.01 ; p=0.025 ; p<0.05 ; p=0.025 ; p<0.05)$ (Table 5).
The depression and stress scores of HCW working over 40 hours per week were statistically significantly higher than those working less than 40 hours per week $(p=0.003, p<0.01 ; p=0.024, p<0.05$, respectively) (Table 5).

During the COVID-19 outbreak, the depression, anxiety, and stress scores of HCW who had a change in their units were statistically significantly higher than those experiencing no changes $(p=0.007, p<0.01 ; p=0.034, p<0.05 ; p=0.001, p<0.01$, respectively) (Table 5).

\section{DISCUSSION}

HCW experience significant stress during infectious outbreaks. COVID-19 is a worldwide major public health problem, which is complex, infectious, and often sensitive. It brings significant difficulties regarding social prevention, control, and pre-pure therapy. Moreover, reports on the psychological impact of SARS on HCW have shown that high levels of distress are common (7).

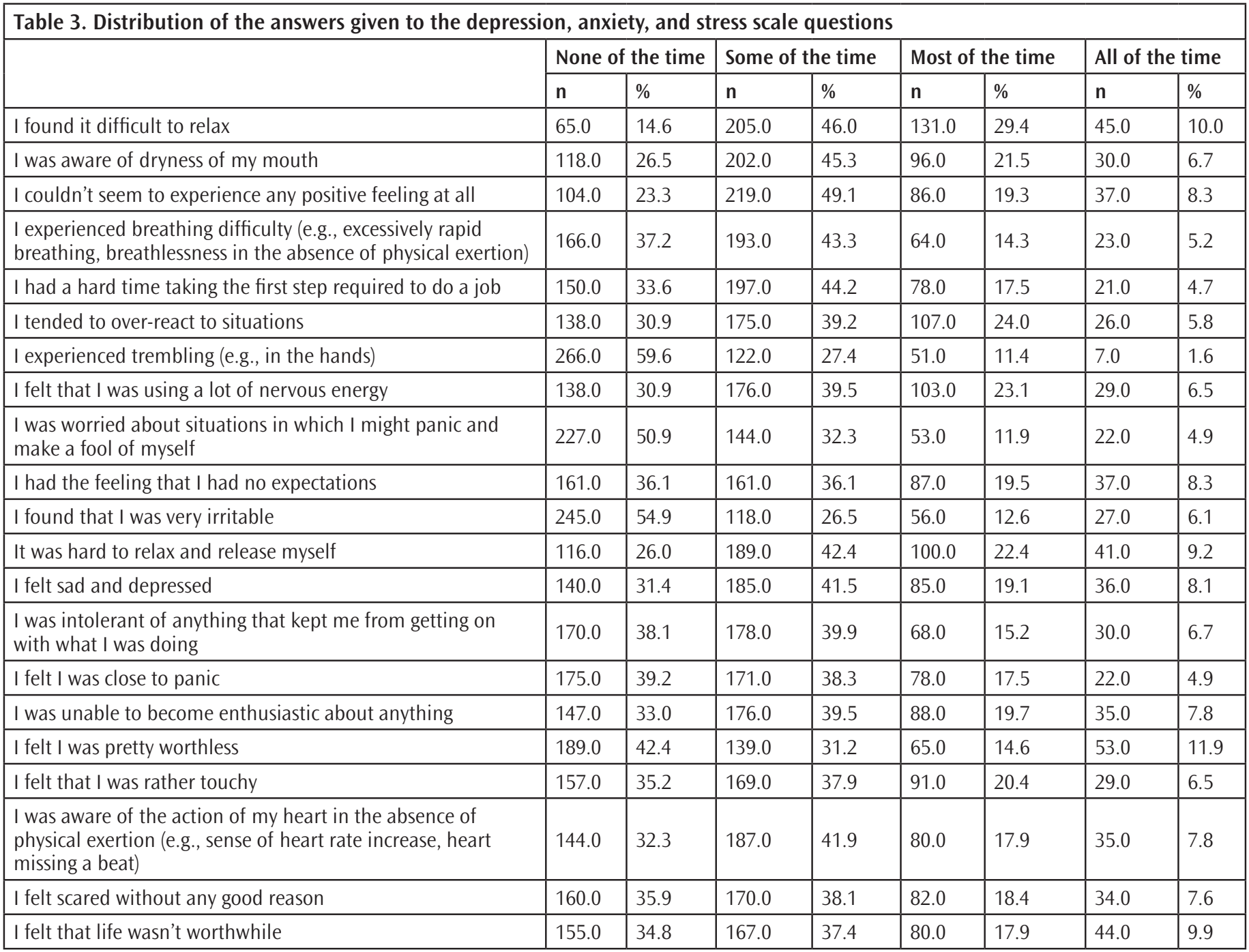




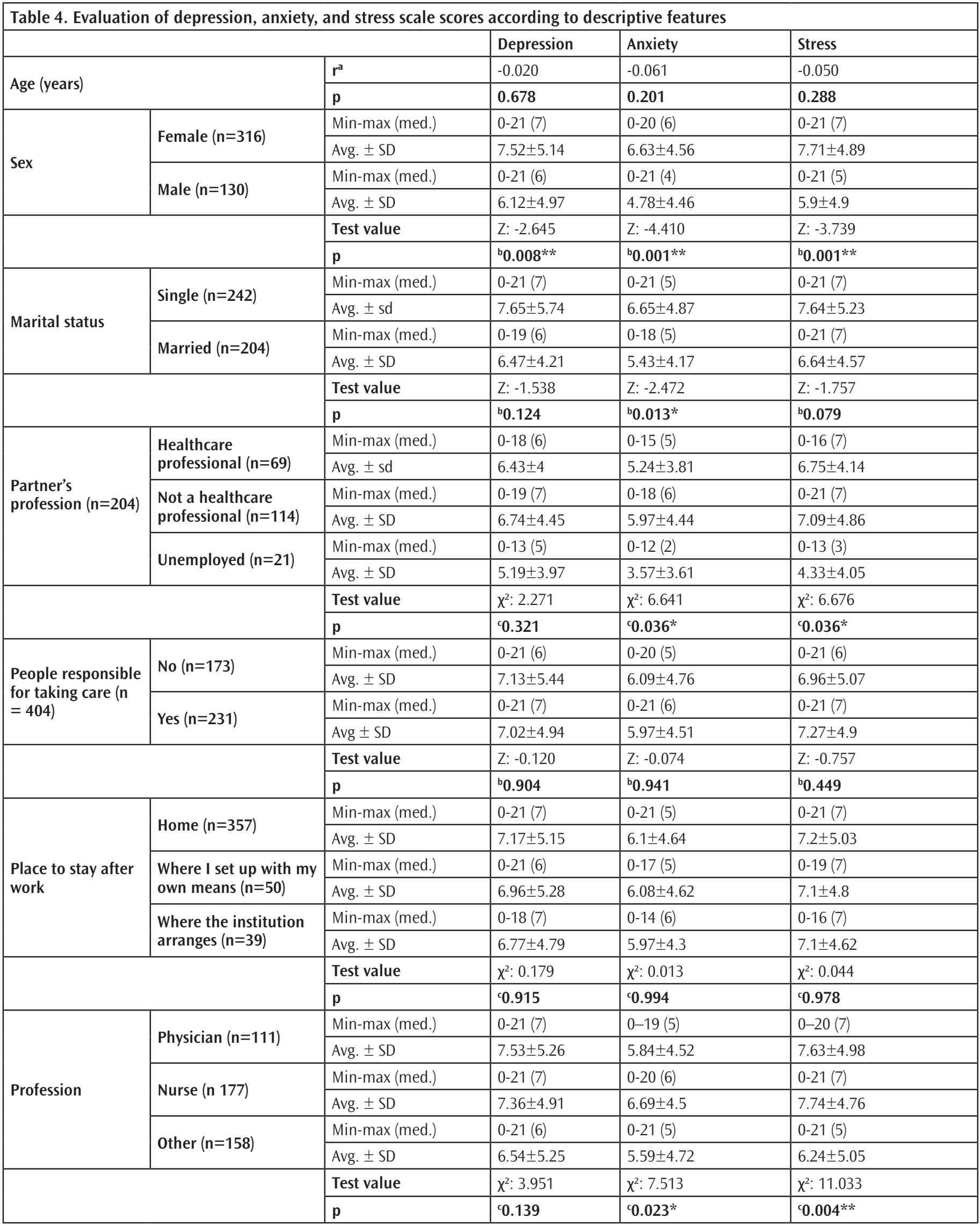




\begin{tabular}{|c|c|c|c|c|c|}
\hline \multicolumn{6}{|c|}{ Table 4. Continued } \\
\hline & & & Depression & Anxiety & Stress \\
\hline \multirow{6}{*}{ Chronic disease } & \multirow{2}{*}{ Yes $(n=80)$} & Min-max (med.) & $0-21(7)$ & $0-21(6)$ & $0-21(7)$ \\
\hline & & Avg. $\pm S D$ & $7.81 \pm 5.34$ & $7.24 \pm 4.84$ & $8.1 \pm 5.52$ \\
\hline & \multirow{2}{*}{ No $(n=366)$} & Min-max (med.) & $0-21(6)$ & $0-20(5)$ & $0-21(7)$ \\
\hline & & Avg. \pm SD & $6.96 \pm 5.07$ & $5.84 \pm 4.52$ & $6.98 \pm 4.81$ \\
\hline & & Test value & Z: -1.257 & Z: -2.478 & Z: -1.406 \\
\hline & & $p$ & ${ }^{b} 0.209$ & ${ }^{b} 0.013^{*}$ & ${ }^{b} 0.160$ \\
\hline \multirow{6}{*}{$\begin{array}{l}\text { Psychological } \\
\text { support request }\end{array}$} & \multirow{2}{*}{ Yes $(n=30)$} & Min-max (med.) & $1-21(8.5)$ & $0-21(8)$ & $1-21(9.5)$ \\
\hline & & Avg. \pm SD & $10.2 \pm 5.59$ & $9.63 \pm 5.46$ & $10.9 \pm 5.25$ \\
\hline & \multirow{2}{*}{ No $(n=416)$} & Min-max (med.) & $0-21(6)$ & $0-20(5)$ & $0-21(7)$ \\
\hline & & Avg. $\pm S D$ & $6.89 \pm 5.03$ & $5.83 \pm 4.43$ & $6.91 \pm 4.83$ \\
\hline & & Test value & Z: -3.157 & Z: -3.884 & Z: -3.930 \\
\hline & & $p$ & ${ }^{\mathrm{b}} 0.002^{* *}$ & ${ }^{\mathrm{b}} 0.001 * *$ & ${ }^{\mathrm{b}} 0.001^{* *}$ \\
\hline
\end{tabular}

\begin{tabular}{|c|c|c|c|c|c|}
\hline & & & Depression & Anxiety & Stress \\
\hline \multirow{8}{*}{ Working experience } & \multirow{2}{*}{$1-5$ years $(n=220)$} & Min-max (med.) & $0-21(7)$ & $0-21(5)$ & $0-21(7)$ \\
\hline & & Avg. $\pm S D$ & $7.55 \pm 5.51$ & $6.5 \pm 4.84$ & $7.65 \pm 5.13$ \\
\hline & \multirow{2}{*}{$6-10$ years $(n=64)$} & Min-max (med.) & $0-21(5.5)$ & $0-18(5)$ & $0-19(5)$ \\
\hline & & Avg. \pm SD & $6.84 \pm 5.36$ & $5.33 \pm 4.48$ & $6.23 \pm 5.1$ \\
\hline & \multirow{2}{*}{$11-20$ years $(n=93)$} & Min-max (med.) & $0-21(7)$ & $0-20(6)$ & $0-21(7)$ \\
\hline & & Avg. $\pm S D$ & $6.74 \pm 4.41$ & $5.87 \pm 4.06$ & $7.04 \pm 4.42$ \\
\hline & \multirow{2}{*}{$\geq 21$ years $(n=69)$} & Min-max (med.) & 0-19 (6) & 0-18 (5) & $0-21(7)$ \\
\hline & & Avg. \pm SD & $6.46 \pm 4.46$ & $5.78 \pm 4.57$ & $6.77 \pm 4.87$ \\
\hline & & Test value & $\chi^{2}: 1.965$ & $x^{2}: 3.646$ & $\chi^{2}: 5.272$ \\
\hline & & $\mathbf{p}$ & ' 0.580 & ${ }^{\prime} 0.302$ & ${ }^{c} 0.153$ \\
\hline \multirow{4}{*}{ Weekly working hours } & \multirow{2}{*}{$\leq 40$ hours $(n=187)$} & Min-max (med.) & $0-21(5)$ & $0-21(5)$ & $0-21(6)$ \\
\hline & & Avg. \pm SD & $6.29 \pm 4.83$ & $5.72 \pm 4.64$ & $6.59 \pm 4.82$ \\
\hline & \multirow{2}{*}{$>40$ hours $(n=259)$} & Min-max (med.) & $0-21(7)$ & $0-20(6)$ & $0-21(7)$ \\
\hline & & Avg. \pm SD & $7.7 \pm 5.26$ & $6.36 \pm 4.56$ & $7.61 \pm 5.02$ \\
\hline & & Test value & Z: -2.999 & Z: -1.775 & Z: -2.256 \\
\hline & & $p$ & ${ }^{\mathrm{b}} 0.003^{* *}$ & ${ }^{\mathrm{b}} 0.076$ & ${ }^{\mathrm{b}} 0.024^{*}$ \\
\hline \multirow{4}{*}{$\begin{array}{l}\text { Change of unit during } \\
\text { pandemic }\end{array}$} & \multirow{2}{*}{ Yes $(n=179)$} & Min-max (med.) & $0-21(7)$ & $0-20(6)$ & $0-21(7)$ \\
\hline & & Avg. \pm SD & $7.72 \pm 4.9$ & $6.41 \pm 4.66$ & $7.59 \pm 4.97$ \\
\hline & \multirow{2}{*}{ No $(n=267)$} & Min-max (med.) & $0-21(6)$ & $0-21(5)$ & $0-21(7)$ \\
\hline & & Avg. \pm SD & $6.7 \pm 5.24$ & $5.87 \pm 4.56$ & $6.91 \pm 4.94$ \\
\hline & & Test value & Z: - -2.681 & Z: -1.344 & Z: -1.592 \\
\hline & & $p$ & ${ }^{b} 0.007^{* *}$ & ${ }^{\mathrm{b}} 0.179$ & ${ }^{\mathrm{b}} 0.111$ \\
\hline \multirow{6}{*}{ Assigned unit ( $n=179)$} & \multirow{2}{*}{$\begin{array}{l}\text { Emergency room } \\
(n=23)\end{array}$} & Min-max (med.) & $0-18(7)$ & $0-13(5)$ & $0-17(7)$ \\
\hline & & Avg. \pm SD & $7.35 \pm 5.36$ & $5.96 \pm 4.11$ & $7.65 \pm 4.78$ \\
\hline & \multirow{2}{*}{$\begin{array}{l}\text { Intensive care unit } \\
(\mathrm{n}=52)\end{array}$} & Min-max (med.) & $0-21(7,5)$ & $0-20(6)$ & $0-21(7)$ \\
\hline & & Avg. $\pm S D$ & $8.52 \pm 5.4$ & $6.9 \pm 5.16$ & $7.94 \pm 5.18$ \\
\hline & \multirow{2}{*}{$\begin{array}{l}\text { Inpatient services } \\
(\mathrm{n}=76)\end{array}$} & Min-max (med.) & $0-21(7)$ & 0-19 (6) & $0-20(7.5)$ \\
\hline & & Avg.土 SD & $7.54 \pm 4.66$ & $6.29 \pm 4.57$ & $7.61 \pm 4.91$ \\
\hline
\end{tabular}




\begin{tabular}{|c|c|c|c|c|c|}
\hline \multicolumn{6}{|l|}{ Table 5. Continued } \\
\hline & & & \begin{tabular}{|l|} 
Depression \\
\end{tabular} & Anxiety & Stress \\
\hline \multirow{4}{*}{ Assigned unit $(n=179)$} & \multirow{2}{*}{ Operating room $(n=1)$} & Min-max (med.) & 12 & 12 & 13 \\
\hline & & Avg.土 SD & 12 & 12 & 13 \\
\hline & \multirow{2}{*}{ Outpatient unit $(n=27)$} & Min-max (med.) & $0-18(7)$ & $0-15(6)$ & $0-16(8)$ \\
\hline & & Avg. \pm SD & $6.85 \pm 4.16$ & $6 \pm 4.42$ & $6.59 \pm 4.98$ \\
\hline & & Test value & $\chi^{2}: 0.878$ & $\chi^{2}: 0.393$ & $\chi^{2}: 0.795$ \\
\hline & & $p$ & \begin{tabular}{|c|} 
\\
\end{tabular} & \begin{tabular}{|c|}
${ }^{\prime} 0.942$ \\
\end{tabular} & \begin{tabular}{|c|} 
\\
\end{tabular} \\
\hline \multirow{4}{*}{$\begin{array}{l}\text { Contact with COVID-19 } \\
\text { patient }\end{array}$} & \multirow{2}{*}{ Yes $(n=384)$} & Min-max (med.) & $0-21(7)$ & $0-21(5)$ & $0-21(7)$ \\
\hline & & Avg. \pm SD & $7.24 \pm 5.1$ & $6.24 \pm 4.57$ & $7.44 \pm 4.95$ \\
\hline & \multirow{2}{*}{ No $(n=62)$} & Min-max (med.) & $0-21(6)$ & $0-19(4)$ & $0-21(5)$ \\
\hline & & Avg. \pm SD & $6.31 \pm 5.25$ & $5.13 \pm 4.75$ & $5.6 \pm 4.71$ \\
\hline & & Test value & Z: -1.496 & Z: -2.119 & Z: -2.826 \\
\hline & & $p$ & b0.135 & '0.034* & ${ }^{\mathrm{b}} 0.005^{* *}$ \\
\hline \multirow{4}{*}{$\begin{array}{l}\text { Contact with mask } \\
\text { wearing COVID-19 patient } \\
(\mathrm{n}=384)\end{array}$} & \multirow{2}{*}{ Yes $(n=304)$} & Min-max (med.) & $0-21(6)$ & $0-21(5)$ & $0-21(7)$ \\
\hline & & Avg. \pm SD & $7.03 \pm 5.08$ & $6.08 \pm 4.53$ & $7.21 \pm 4.93$ \\
\hline & \multirow{2}{*}{ No $(n=80)$} & Min-max (med.) & \begin{tabular}{|l|}
$0-21(7.5)$ \\
\end{tabular} & \begin{tabular}{|l|}
$0-19(6.5)$ \\
\end{tabular} & $0-20(8)$ \\
\hline & & Avg. \pm SD & $8.03 \pm 5.13$ & $6.89 \pm 4.67$ & $8.31 \pm 4.99$ \\
\hline & & Test value & Z: -1.758 & Z: -1.446 & Z: -1.808 \\
\hline & & $p$ & \begin{tabular}{|l|}
$\mathrm{b} 0.079$ \\
\end{tabular} & ${ }^{\mathrm{b}} 0.148$ & ${ }^{\mathrm{b}} 0.071$ \\
\hline \multirow{4}{*}{$\begin{array}{l}\text { Colleagues diagnosed with } \\
\text { CoVID-19 }\end{array}$} & \multirow{2}{*}{ Yes $(n=396)$} & Min-max (med.) & $0-21(7)$ & $0-21(6)$ & $0-21(7)$ \\
\hline & & Avg. \pm SD & $7.41 \pm 5.07$ & $6.34 \pm 4.6$ & $7.55 \pm 4.93$ \\
\hline & \multirow{2}{*}{ No $(n=50)$} & Min-max (med.) & $0-21(3.5)$ & $0-19(3)$ & $0-19(4)$ \\
\hline & & Avg. \pm SD & $4.7 \pm 4.95$ & $4.12 \pm 4.2$ & $4.3 \pm 4.17$ \\
\hline & & Test value & Z: -3.991 & Z: -3.683 & Z: -4.657 \\
\hline & & $p$ & ${ }^{\mathrm{b}} 0.001^{* *}$ & ${ }^{\mathrm{b}} 0.001^{* *}$ & ${ }^{\mathrm{b}} 0.001^{* *}$ \\
\hline \multirow{4}{*}{$\begin{array}{l}\text { Acquaintances diagnosed } \\
\text { with COVID-19 outside } \\
\text { work place }\end{array}$} & \multirow{2}{*}{ Yes $(n=166)$} & Min-max (med.) & $0-21(7)$ & $0-21(6)$ & $0-21(7)$ \\
\hline & & Avg. \pm SD & $7.91 \pm 5.18$ & $6.75 \pm 4.82$ & $8.08 \pm 5$ \\
\hline & \multirow{2}{*}{ No $(n=280)$} & Min-max (med.) & $0-21(6)$ & $0-19(5)$ & $0-21(7)$ \\
\hline & & Avg. \pm SD & $6.64 \pm 5.05$ & $5.7 \pm 4.43$ & $6.65 \pm 4.86$ \\
\hline & & \begin{tabular}{|l} 
Test value \\
\end{tabular} & Z: -2.647 & Z: -2.236 & Z: - -2.955 \\
\hline & & $p$ & ${ }^{\mathrm{b}} 0.008^{* *}$ & ${ }^{\mathrm{b}} 0.025^{*}$ & ${ }^{b} 0.003^{* *}$ \\
\hline
\end{tabular}

Many HCW were emotionally affected during the SARS outbreak. Therefore, it is very important for health institutions to provide psychosocial support and intervention to HCW during outbreaks (13). Understanding the psychological impact of the COVID-19 outbreak among HCW will guide us to take the necessary measures and plan improvements.

Of the $446 \mathrm{HCW}$ participating in our study, $70.9 \%$ were women, and DASS-21 scores in women were significantly higher than men. In terms of profession, $24.9 \%$ of the participants were physicians, and $39.7 \%$ were nurses. The anxiety scores of the participating nurses and stress scores of participating physicians and nurses were higher than other occupational groups. The anxiety score of single HCW was also higher than married one. Similar to our study, the study investigating the psychological impact of the SARS outbreak in 2003 on HCW in Singapore reported that single HCW were at higher risk than married ones. It has been reported that single HCW are 1.4 times more likely to experience psychiatric symptoms than married ones (13). In a study including 469 HCW during the H1N1 pandemic, nurses were also shown to be more worried than other healthcare staff (14). In numerous studies conducted in the UK, 28$32 \%$ of the doctors and nurses achieved a score above the "emotional distress" threshold in the 12-Item General Health Questionnaire (15-17). 
Long weekly working hours can cause an increase in stress related to COVID-19 infection, caused by respiratory droplets and close contact transmission. Ran Li et al. showed that significant COVID-19 infection rates were detected connected to the daily working hours. Depending on the risks of the workplaces of HCW, it is recommended that the hours of duty be limited to less than 10 hours a day (3). HCW in China have long working hours, exceeding an average of 54 hours per week (18). In our study, it was observed that $58.1 \%$ of the HCW worked over 40 hours. Depression and stress scores of HCW working more than 40 hours a week were higher compared with those working 40 hours a week or less. Long working hours will probably increase the risk of infection for HCW, while moderate working hours will benefit the employee's safety. It can be said that long working hours increase the risk of infection in employees, as well as causing psychological effects, which may be associated with fear of infection.

In our study, the stress, depression, and anxiety scores of 384 (86.1\%) HCW, who were in contact with patients diagnosed with COVID-19, were higher than HCW who were not in contact with the patients. In a study including $1257 \mathrm{HCW}$ working in the clinic of COVID-19 patients in 34 hospitals in China, it was reported that the symptoms of depression, anxiety, and distress in nurses, women, and frontline HCW were more severe than other HCW (19). In a study examining traumatization in teams that helped control COVID-19, nurses who were in close contact with patients diagnosed with COVID-19 and who were directly exposed to their physical and psychological cases were prone to traumatization (20). In another study conducted during the COVID-19 outbreak, the prevalence of stress related insomnia among HCW was $36.1 \%$, and during the SARS outbreak, it was $34.2 \%$ in Hong Kong and 37\% in Taiwan (8). Similar to the results of our study, in a study conducted in Singapore including HCW who also worked hard during the epidemic, 68 participants (14.5\%) were found positive for anxiety, 42 (8.9\%) for depression, and 31 (6.6\%) for stress (21). During the H1N1 influenza pandemic, a study including HCW reported that $56.7 \%$ of HCW were worried about the pandemic and their anxiety levels were moderately high, and $20.7 \%$ presented scores that indicated mild-to-moderate psychological distress (14). For this reason, precautions should be taken against the psychological problems that may occur in HCW who participate actively in the pandemic process.

88.8\% of HCW, who participated in our study, were diagnosed with COVID-19 among their colleagues. In our hospital, which serves as a pandemic hospital, 343 HCW were diagnosed with
COVID-19 between 15 March and 30 August. China reported that, by February 25, 2020, 3387 infected HCW were in Hubei only, of which at least 18 died (22). As HCW participate actively in the treatment and care of patients during a pandemic, the risks of contracting the disease increase. This affects the psychology of HCW.

$37.2 \%$ of the participants stated they have relatives who have been diagnosed with COVID-19, outside their workplace. Anxiety, depression, and stress scores of HCW with any relatives diagnosed with COVID-19, outside the workplace, were found to be statistically significantly higher than those without. During the H1N1 pandemic, very few HCW (6.6\%) restricted their social contact, and fewer (3.8\%) were isolated by family members and friends for working in the hospital. However, the degree of anxiety was significantly associated with the restriction of social contacts (14). We think that HCW's fear of infecting their families and therefore being isolated from them can increase their stress.

\section{Study Limitations}

Our study has limitations. Data obtained from self-reported answers were not verified against medical records. Performing similar studies with larger samples on how to protect HCW will provide significant benefits to the public health. We hope that our findings will contribute to the work of psychological studies and support strategies that can minimize the psychological impact, anxiety, depression, and stress during the COVID-19 pandemic.

\section{CONCLUSION}

The pandemic process affects HCW even more with the exposure to patients diagnosed with COVID-19. Psychological support programs should be planned, and psychosocial support and intervention should cover all HCW. Identifying mental health problems such as depression, anxiety, and stress and the factors affecting them will enable developing appropriate screening and intervention programs for HCW. With the improvements and interventions, HCW can go through this intense process with minimal damage.

\section{Ethics}

Ethics Committee Approval: The Ethics Committee of the University of Health Sciences Turkey, Bakırköy Dr. Sadi Konuk Training and Research Hospital, approved the questionnaire and methodology for this study (approval number: 2020/145). 
Informed Consent: The participants' consent to participate in the study was requested personally from each individual.

Peer-review: Externally peer-reviewed.

\section{Authorship Contributions}

Concept: Ö.P., F.C., Design: Ö.P., F.C., Data collection or Processing: Ö.P., F.C., Analysis or Interpretation: Ö.P., Literature Search: Ö.P., F.C., Writing: Ö.P., F.C.

Conflict of Interest: No conflict of interest was declared by the authors.

Financial Disclosure: The authors declared that this study received no financial support.

\section{REFERENCES}

1. Zhou F, Yu T, Du R, Fan G, Liu Y, Liu Z, et al. Clinical course and risk factors for mortality of adult inpatients with COVID-19 in Wuhan, China: a retrospective cohort study. Lancet 2020;395:1054-62.

2. WHO Coronavirus (COVID-19) Disease Dashboard. Available from: https://covid19.who.int/ Accessed on 25.06.2020.

3. Ran L, Chen X, Wang Y, Wu W, Zhang L, Tan X. Risk Factors of Healthcare Workers With Coronavirus Disease 2019: A Retrospective Cohort Study in a Designated Hospital of Wuhan in China. Clinical Infectious Diseases 2020;71:2218-21.

4. Turkish Ministry of Health information meeting. Available at: https:// tr.euronews.com/saglık-bakan-koca-covid-19-la-mucadelede-gelinenson-noktay-degerlendiriyor. Accessed on 03.06.2020.

5. Centers for Disease Control and Prevention (CDC). Severe acute respiratory syndrome--Taiwan, 2003. MMWR Morb Mortal Wkly Rep 2003;52:461-6

6. Wu P, Fang Y, Guan Z, Fan B, Kong J, Yao Z, et al. The psychological impact of the SARS epidemic on hospital employees in China: exposure, risk perception, and altruistic acceptance of risk. Can J Psychiatry 2009;54:302-11.

7. Maunder RG, Lancee WJ, Rourke S, Hunter JJ, Goldbloom D, Balderson K, et al. Factors associated with the psychological impact of severe acute respiratory syndrome on nurses and other hospital workers in Toronto. Psychosom Med 2004;66:938-42.

8. Zhang C, Yang L, Liu S, Ma S, Wang Y, Cai Z, et al. Survey of Insomnia and Related Social Psychological Factors Among Medical Staff Involved in the 2019 Novel Coronavirus Disease Outbreak. Front Psychiatry 2020;11:306.
9. Clegg A. Occupational stress in nursing: a review of the literature. J Nurs Manag 2001;9:101-6.

10. Lovibond SH, Lovibond PF. Manual for the Depression Anxiety Stress Scales, (2nd ed.). Sydney, Australia: Pychology Foundation of Australia,1995.

11. Lovibond PF, Lovibond SH. The structure of negative emotional states: comparison of the Depression Anxiety Stress Scales (DASS) with the Beck Depression and Anxiety Inventories. Behav Res Ther 1995;33:335-43.

12. Sarıçam H. The Psychometric Properties of Turkish Version of Depression Anxiety Stress Scale-21 (DASS-21) in Community and Clinical Samples. JCBPR 2018;7:19-30.

13. Chan AO, Huak CY. Psychological impact of the 2003 severe acute respiratory syndrome outbreak on health care workers in a medium size regional general hospital in Singapore. Occup Med (Lond) 2004;54:1906.

14. Goulia P, Mantas C, Dimitroula D, Mantis D, Hyphantis T. General hospital staff worries, perceived sufficiency of information and associated psychological distress during the A/H1N1 influenza pandemic. BMC Infect Dis 2010;10:322.

15. Firth-Cozens J. Emotional distress in junior house officers. Br Med J (Clin Res Ed) 1987;295:533-6.

16. Ramirez AJ, Graham J, Richards MA, Cull A, Gregory WM, Leaning MS, et al. Burnout and psychiatric disorder among cancer clinicians. $\mathrm{Br}$ J Cancer 1995;71:1263-9.

17. Hetherington A. The Exent and Source of Stress in Emergency Care. Report no: 9110,1993, UK, Cranfield University.

18. Wen J, Hao T, Hu X. Doctor's Workload in China: A Status-quo Study. Chin J Evid-Based Med 2015;15:133-6.

19. Lai J, Ma S, Wang Y, Cai Z, Hu J, Wei N, et al. Factors Associated With Mental Health Outcomes Among Health Care Workers Exposed to Coronavirus Disease 2019. JAMA Netw Open 2020;3:e203976.

20. Li Z, Ge J, Yang M, Feng J, Qiao M, Jiang R, et al. Vicarious traumatization in the general public, members, and non-members of medical teams aiding in COVID-19 control. Brain Behav Immun 2020;88:916-9.

21. Tan BYQ, Chew NWS, Lee GKH, Jing M, Goh Y, Yeo LLL, et al. Psychological Impact of the COVID-19 Pandemic on Health Care Workers in Singapore. Ann Intern Med 2020;173:317-20.

22. Schwartz J, King CC, Yen MY. Protecting Healthcare Workers During the Coronavirus Disease 2019 (COVID-19) Outbreak: Lessons From Taiwan's Severe Acute Respiratory Syndrome Response. Clin Infect Dis 2020;71:858-60. 